\title{
EFEKTIFITAS PIJAT TERHADAP KUALITAS TIDUR BAYI USIA 3-6 BULAN DI KLINIK CAHAYA BUNDA
}

\author{
Mailiza Cahyani ${ }^{1)}$,Betty Prastuti ${ }^{2)}$ \\ Program Studi Ilmu Kesehatan Masyarakat, STIKes Payung Negeri Pekanbaru \\ Jl. Tamtama No. 6 Labuh Baru Timur Pekanbaru - Riau - Indonesia \\ E-mail :faiza_111008@yahoo.co.id ${ }^{1)}$
}

Kata Kunci:

Pijat, Bayi, Kualitas Tidur

Keywords:

Massage, Baby, Sleep Quality

Info Artikel

Tanggal dikirim:20 Juni 2020

Tanggal direvisi:27 Juli 2020

Tanggal diterima:27 Juli 2020

DOI Artikel:

10.36341/jomis.v4i2.1358

Creative Commons AttributionNonCommercial-ShareAlike 4.0 International License.

\begin{abstract}
ABSTRAK
Bagi bayi, tidur adalah prioritas utama. Saat tidur terjadi repair neuro brain $\pm 75 \%$ hormon pertumbuhan diproduksi. Dengan diberi pijatan bayi dapat tertidur dengan lelap, untuk memenuhi kebutuhan tidur bayi adalah dengan pijatan. Bayi yang dipijat dapat tidur dengan lelap, sehingga saat bangun daya konsentrasinya akan lebih penuh. Pada studi pendahuluan, ibu ibu yang memiliki bayi usia 3-6 bulan menyatakan bayi sering terbangun dan menangis setiap 1 hingga 2 jam tidur, dan tidur bayi juga kurang lelap di lihat dari bayi akan menangis jika ibu bergerak menjauhi bayi. Metode penelitian: analitik kuantittatif dengan jenis penelitian quasy experiment. Populasi penelitian ini adalah semua bayi usia 3-6 bulan yang berkunjung ke klinik cahaya bunda yang berjumlah 68 bayi. Teknik Sampling yang digunakan total sampling Pengumpulan data dengan melakukan pijat, observasi dan kuesioner. Tujuan penelitian untuk mengetahui efektifitas pijat terhadap kualitas tidur bayi di Klinik Cahaya Bunda, dimana dengan Analisis uji statistik chi square dengan derajat kepercayaan 95\% $p=0,05$ didapatkan pijat efektif untuk meningkatkan kualitas tidur bayi dengan $(\mathrm{p}=0,003)$. Sehingga baiknya lilinik dapat menerapkan pijat bayi sebagai asuhan rutin kepada bayi dan dapat menjadi salah satu standar asuhan yang dapat memberikan pemenuhan kebutuhan rasa aman dan nyaman pada bayi.
\end{abstract}

\begin{abstract}
Sleep is a top priority for babies, because this is when neuro brain repair occurs and approximately $75 \%$ of growth hormone is produced. One of the methods that can be used to fulfill your baby's sleep needs is with a massage. Babies who are massaged can sleep soundly, whereas when they wake up, their concentration will be fuller. In a preliminary study conducted on mothers who have infants aged 3-6 months stated that babies often wake up and cry every 1 to 2 hours of sleep, and babies are also less sleepy if the mother moves away from the baby. Research methods: quantitative analysis with quasy experiment research type. The population of this research is all infants aged 3-6 months who visit the maternal light clinic, amounting to 68 babies. The sampling technique used is total sampling. Data collection by doing massage, observation and questionnaire. The purpose of this research is to find out how effective massage is to sleep quality of babie, where with chi square statistical analysis with a degree of confidence $95 \% p=0.05$ obtained an effective massage to improve the quality of sleep of infants with $(p=0.003)$. So that it is good for Kilinik to apply baby massage as a routine care for babies and can be one of the standards of care that can provide the fulfillment of the need for security and comfort in babies.
\end{abstract}

\section{PENDAHULUAN}

Menurut Prasetiyono 2018, Pijat bayi dapat meningkatkan kualitas dan kuantitas tidur bayi sehingga merangsang hormon endorphin untuk menurunkan nyeri dan akan bayi menjadi tenang akhirnya mengurangi frekuensi menangis bayi. Rumah sakir di beberapa negara seperti Amerika Serikat (AS), Hongkong, Cina, dan Filipina, sudah memasukkan pijat bayi dalam pelayanan kesehatan bayi di rumah sakitnya. Data klinis terbaru hasil riset menunjukan bukti -bukti 
bahwa pijat bayi mampu mengurangi masalah tidur pada bayi sebesar $47 \%$ [2]

Penelitian T. Field dari Miami, AS, 2010, menyatakan dengan terapi pijat tidur bayi lebih lelap. Terapi pijat merupakan bagian dari pengobatan alternatif, namun saat ini sudah diterima secara empiris sebagai sarana untuk membantu pertumbuhan, mengatasi rasa sakit, menjadi lebih siaga, mengatasi depresi dan meningkatkan fungsi sistem imun pada bayi yang baru lahir. Hasil penelitian Touch Research Institusi Amerika mendapati bayi yang diberikan pijatan lebih aktif dan waspada, dengan pijatan juga membuat syaraf bayi yang dipijat menjadi lebih cepat matang daripada bayi yang tidak mendapatkan pijatan. Hasil penelitian ini menyebutkan bahwa pijatan menyebabkan keluarnya hormon melatonin, hormone tersebut membuat bayi dapat memiliki pola tidur yang teratur [3]

Dengan memberi pijatan kebutuhan tidur bayi dapat terpenuhi. Bayi dapat tidur dengan lelap dan pada saat bangun, daya konsentrasinya akan lebih penuh [1]. Tidur nyenyak sangat dibutuhkan bagi pertumbuhan bayi, karena saat pertumbuhan otak bayi mencapai akan puncaknya saaat tidur. Pada saat tidur tubuh bayi memproduksi hormon untuk meningkatkan pertumbuhan bayi tiga kali lebih banyak dibandingkan ketika bayi terbangun [4].

Bayi yang tidur selama 5-6 jam dan esoknya bagun sengan segara berarti memiliki kualitas tidur yang baik. Bayi yang tidur mengalami perbaikan sel otak dan produksi hormon pertumbuhan, oleh karena itu, kualitas tidur bayi perlu dijaga. Kualitas tidur bayi dapat dilihat dari tiga kriteria yaitu cara tidurnya, kenyamanan tidur dan pola tidur. Bayi yang tidur cukup dan tidak sering terbangun, lebih bugar dan tidak mudah rewel keesokan harinya. Tidur berdampak besar pada kesehatan mental, emosi dan fisik serta sistem imunitas tubuh. Mengingat akan pentingnya waktu tidur bagi perkembangan bayi maka kebutuhan tidurnya harus diperhatikan agar tidak berdampak buruk bagi perkembangannya. Dengan kualitas tidur yang baik, pertumbuhan dan perkembangan bayi dapat dicapai secara optimal. [5]

Tidur dengan kualitas dan kuantitas yang baik dapat membantu perkembangan bayi [6]. Klinik Cahaya Bunda merupakan salah satu praktek bidan mandiri di Pekanbaru yang melayani berbagai perawatan ibu dan anak. Salah satunya perawatan pijat bayi yang sangat diminati masyarakat kota Pekanbaru. Dalam studi pendahuluan yang dilakukan pada ibu ibu yang memiliki bayi usia 3-6 bulan menyatakan bayi sering terbangun dan menangis setiap 1 hingga 2 jam tidur, dan tidur bayi juga kurang lelap di lihat dari bayi akan menangis jika ibu bergerak menjauhi bayi.

\section{TINJAUAN PUSTAKA}

Menurut Potter dan Perry (2012)[7], tidur merupakan suatu keadaan berulang, perubahan status kesadaran yang terjadi selama suatu periode waktu tertentu. Jika orang bisa tidur dengan cukup maka setelahnya merasa tenaganya pulih. Tidur adalah proses yang normal dan alamiah merupakan kondisi keadaan istirahat yang diperlukan oleh manusia secara rutin. Keadaan tidur ini ditandai oleh berkurangnya gerakan tubuh dan penurunan kewaspadaan terhadap lingkungan sekitarnya [4]. Tidur adalah kebutuhan semua manusia dan untuk kesehatan fisik dan psikologis. Tidur merupakan proses perbaikan dan pertumbuhan jaringan [8].

Beberapa penelitian menyatakan bahwa pulihnya tenaga setelah tidur menunjukkan bahwa tidur memberikan waktu 
untuk perbaikan dan penyembuhan system tubuh untuk periode keterjagaan yang berikutnya. Tidur merupakan prioritas utama bagi bayi. Tumbuh kembang bayi sangat tergantung dari kualitas dan kuantitas tidur. Tanpa tidur, bayi tidak mampu tumbuh optimal, karena pada saat tidur terjadi perbaikan (repair) sel-sel di dalam organ otak dan hormone pertumbuhan diproduksi sekitar $75 \%$ [4].

Kualitas tidur juga berpengaruh pada perkembangan emosi bayi selain perkembangan fisik. Kuantitas dan kualitas tidur bayi harus terpenuhi dengan baik. Bayi yang tidur dengan cukup tanpa terbangun berulang ulang dapat bangun pada kesokan harianya dengan lebih buga. Kebutuhan tidur pada bayi sesuai usianya perlu mendapat perhatian dari keluarga agar nantinya bayi dapat mencapai pertumbuhan dan perkembangan yang optimal [5].

Pijat adalah terapi sentuh tertua yang dikenal manusia dan yang paling popular. Pijat telah lama dilakukan hamper diseluruh dunia termasuk di Indonesia dan diwariskan secara turun temurun. Pijat merupakan aplikasi tekanan pada jaringan lunak tubuh seperti kulit, otot, tendon dan ligament. Pijat diimplementasikan pada daerah kulit karena mampu merasakan sentuhan yang mendatangkan efek bagi pikiran dan tubuh seseorang. Gerakan pijat dapat melemaskan otot sehingga peredaran darah menjadi lancar, memberikan makna komunikasi, memberikan rasa aman, hangat, menyenangkan dan menstimulasi produksi endorphin secara alami [9].

Pijat bayi disebut juga stimulasi touch atau terapi sentuh. Disebut terapi sentuh karena melalui pijat bayi inilah akan terjadi komunikasi melaui sentuhan antara ibu dan bayinya. Pijat bayi terbagi dalam berbagai bentuk jenis gerakan, terapi dan tujuan. Selain berfungsi sebagai terapi yang banyak memberikan manfaat, pijat bayi ini juga merupakan cara ungkapan cinta orang tua ke anaknya. Sentuhan yang dirasakan bayi pada kulitnya berdampak positif bagi perkembangan fisik, emosi dan tumbuh kembang anak [10]. Manfaat pijat bayi adalah membantu dalam rangsangan syaraf motorik, merubah pola tidur yang buruk menjadi baik, membantu proses pencernaan dan memberikan ketenangan emosional, selain juga menyehatkan tubuh dan otot-ototnya.Bayi yang dipijat dengan baik dan teratur dapat tumbuh lebih sehat dan berkembang lebih baik.Terapi sentuh, terutama pijat menghasilkan perubahan fisiologis yang menguntungkan dan dapat diukur secara ilmiah. Menurut [1] manfaat pijat bayi antara lain sebagai berikut :

1. Meningkatkan imunitas

2. Memperbaiki jalannya peredaran darah dan pernafasan

3. Merangsang fungsi pencernaan serta proses pembuangan

4. Meningkatkan kenaikan berat badan

5. Mengurangi keadaan stress dan ketegangan

6. Meningkatkan kesiapsiagaan

7. Meningkatkan tingkat kualitas tidur bayi

8. Meningkatkan hubungan batin antara ibu dan bayinya

9. Mengurangi keluhan kembung dan sakit perut pada bayi

Faktor-faktor yang Harus Diperhatikan Dalam Pijat Bayi[8]

1. Pelaksanaan Pemijatan Bayi

Pijat bayi dapat segera dimulai setelah bayi dilahirkan, sesui keinginan orang tua. Dengan lebih cepat mengawali pemijatan, bayi akan mendapatkan keuntungan yang lebih besar. Apalagi jika pemijatan dapat dilakukan setiap hari dari sejak kelahiran sampai bayi berusia 6-7 bulan. Pemijatan 
dapat dilakukan pada waktu-waktu berikut ini : Pagi hari, pada saat orang tua dan anak siap untuk memulai hari baru dan malam hari, sebelum tidur. Ini sangat baik untuk membantu bayi tidur lebih nyenyak.

2. Persiapan Sebelum Memijat

Menurut Roesli (2013) [1] sebelum melakukan pemijatan harus memperhatikan hal-hal berikut ini:
a. Tangan harus dibersihkan dan dan suhunya sebaiknya hangat
b. Hindari kuku panjang dan memiliki hiasan, agar kuku dan perhiasan tidak mengakibatkan goresan pada kulit bayi
c. Ruang untuk memijat bayi harus diupayakan hangat dan tidak pengap
d. Bayi sudah kenyang atau sedang tidak lapar
e. Sediakan waktu minimal selama 15 menit guna melakukan seluruh tahap- tahap pemijatan tanpa gangguan
f. Duduklah pada posisi nyaman dan tenang

g. Letakkan bayi diatas Siapkanlah handuk, popok bayi, baju permukaan kain yang rata, lembut, dan bersih ganti, dan minyak bayi (baby oil atau lotion)

h. Berikan aba-aba sebelum pemijatan, dengan cara membelai wajah dan kepala bayi sambil mengajaknya bicara

i. Akhiri dengan peregangan. Setelah melakukan persiapan itu, pemijatan bisa dimulai.

Pijat bayi disebut juga stimulasi touch atau terapi sentuh. Pijat bayi berkembang dalam berbagai bentuk jenis gerakan, terapi dan tujuan. Selain sebagai salah satu terapi yang banyak memberikan manfaat, pijat bayi ini juga merupakan salah satu cara pengungkapan kasih sayang antara orang tua dengan anak. Melalui sentuhan pada kulit berdampak luar biasa pada perkembangan fisik, emosi dan tumbuh kembang anak. [4]

\section{METODE}

Penelitian ini merupakan penelitian analitik kuantittatif dengan jenis penelitian quasy experiment. Populasi penelitian ini adalah semua bayi usia 3-6 bulan yang berkunjung ke klinik cahaya bunda yang berjumlah 68 bayi dengan teknik total sampling. Kriteria inkulusi dalam penelitian ini adalah seluruh ibu yang pernah melakukan pemeriksaan di Klinik Cahaya Bunda dan bersedia menjadi responden peneliti. Pengumpulan data pijat bayi dilakukan dengan melakukan pijat secara langsung pada 34 bayi usia 3-6 bulan yang telah di setujui oleh orang tua bayi kemudian dilakukan observasi dengan memberikan kuesioner kepada ibu tentang kualitas tidur bayi. Untuk bayi yang tidak diberikan pijat setelah ibu menyetatujui untuk di wawancara ibu menjawab kuesioner tantang kualitas tidur. Pengolahan Data menggunakan komputerisasi dengan Analisis uji statistik chi square dengan derajat kepercayaan $95 \%$ $p=0,05$.

\section{HASIL DAN PEMBAHASAN}

\section{Data Univariat}

Distribusi responden disajikan pada Tabel 1. Tabel 1 Distribusi Frekuensi Responden

\begin{tabular}{clcc}
\hline No & \multicolumn{1}{c}{ Variabel } & Frekuensi & $\begin{array}{c}\text { Persentase } \\
(\mathbf{\%})\end{array}$ \\
\hline $\mathbf{1}$ & $\begin{array}{l}\text { Pijat Bayi } \\
\text { Tidak dilakukan } \\
\text { pijat bayi }\end{array}$ & 34 & 50,0 \\
& $\begin{array}{l}\text { Dilakukan pijat } \\
\text { bayi }\end{array}$ & 34 & 50,0 \\
\hline$\quad$ Jumlah & 68 & 100 \\
\hline $\mathbf{2}$ & Kualitas tidur bayi & & \\
& $\begin{array}{l}\text { Bermasalah } \\
\text { Tidak bermasalah }\end{array}$ & 29 & 42,6 \\
& Jumlah & 68 & 57,4 \\
\hline
\end{tabular}

110 
Sumber: Data Primer Hasil Penelitian, 2020

Berdasarkan tabel 1 didapatkan responden yang tidak dilakukan pijat bayi sebanyak $34(50 \%)$, dilakukan pijat bayi 34 (50\%). Kualitas tidur bermasalah 29 (42,6\%) dan kualitas tidur tidak bermasalah 39 $(57,4 \%)$.

Tabel 2 Efektifitas Pijat terhadap Kualitas Tidur Bayi di Klinik Cahaya Bunda

\begin{tabular}{|c|c|c|c|c|c|c|c|}
\hline \multirow{3}{*}{ Variabel } & \multicolumn{5}{|c|}{ Kualitas Tidur Bayi } & \multirow{3}{*}{$\begin{array}{c}P \\
\text { Val } \\
u e\end{array}$} & \multirow{3}{*}{$\begin{array}{c}\text { OR } \\
(95 \% \mathrm{CI})\end{array}$} \\
\hline & \multicolumn{2}{|c|}{$\begin{array}{c}\text { Tidur } \\
\text { Bermasalah }\end{array}$} & \multicolumn{2}{|c|}{$\begin{array}{c}\text { Tidur } \\
\text { tidak } \\
\text { bermasalah }\end{array}$} & Total & & \\
\hline & $\mathrm{N}$ & $\%$ & $\mathrm{~N}$ & $\%$ & $\mathrm{n}(\%)$ & & \\
\hline \multicolumn{8}{|l|}{ Pijat Bayi } \\
\hline Tidak dilakukan & 20 & 58.8 & 14 & 41.2 & $34(100)$ & 0.007 & $3.968(1.42$ \\
\hline Dilakukan & 9 & 26.5 & 25 & 73.5 & $34(100)$ & & $6-11.040)$ \\
\hline Total & 29 & 42.6 & 39 & 57.4 & $68(100)$ & & \\
\hline
\end{tabular}

Sumber : Data Primer Hasil Penelitian, 2020

Berdasarkan hasil analisis bivariat pada tabel 2 dapat di simpulkan bahwa pijat bayi efektif dalam meningkatkan kualitas tidur bayi. Responden yang tidak dilakukan pijat mempunyai kualitas tidur bermasalah 3,9 kali dibandingkan responden yang melakukan pijat.

Pijat bayi disebut juga stimulasi touch atau terapi sentuh. Pijat bayi terbagi dalam berbagai bentuk jenis gerakan, terapi dan tujuan. Selain sebagai jenis terapi yang banyak memberikan manfaat, pijat bayi ini juga merupakan salah satu cara bentuk cinta ibu ke anaknya. Melalui sentuhan pada kulit berdampak positif pada perkembangan fisik, emosi dan tumbuh kembang anak.[4]

Peningkatan kualitas tidur pada bayi yang dilakukan pijat bayi disebabkan karena adanya peningkatan kadar sekresi serotonin yang dihasilkan pada saat pemijatan. Menurut Roesli [1] bahwa pijat dapat meningkatkan kadar serotonin yang akan menghasilkan melatonin yang berperan dalam tidur dan

\section{Data Bivariat}

Setelah dilakukan analisa silang dapat diketahui pengaruhpijat terhadap kualitas tidur bayi usia 3-6 di Klinik Cahaya Bunda, hasil analisa disajikan pada Tabel 2. 
pijat bayi dan kualitas tidur bayi $(\mathrm{p}=0,003)$. Ini menunjukkan bahwa pijat bayi efektif dalam memberikan pengaruh terhadap kualitas tidur bagi bayi.

Penelitian ini sejalan dengan penelitian yang dilakukan oleh Dewi dkk (2014)[11] tentang pengaruh pemijatan terhadap kualitas tidur bayi usia 3-4 bulan di Posyandu Gelatik Dan Nuri Kelurahan Tanjungunggat Wilayah Kerja Puskesmas Sei Jang Kota Tanjung Pinang. Hasil uji statistik didapatkan ada perbedaan yang bermakna antara frekuensi terbangun bayi sebelum dan sesudah pemijatan $(\mathrm{p}=0,001)$.

Hasil penelitian menunjukkan bahwa bayi yang dilakukan pijat dapat meningkatkan kualitas tidurnya. Bayi yang tidur cukup tanpa sering terbangun akan lebih bugar dan tidak gampang rewelkeesokan harinya sehingga bayi tumbuh menjadi sehat.

\section{KESIMPULAN}

Simpulan penelitian ini menunjukkan pijat efektif untuk meningkatkan kualitas tidur bayi. Responden yang tidak dilakukan pijat mempunyaikualitas tidur bermasalah 3,9 kali dibandingkan responden yang melakukan pijat.

Saran kepada klinik agar klinik dapat menerapkan pijat bayi sebagai asuhan rutin kepada bayi dan dapat menjadi salah satu standar asuhan yang dapat memberikan pemenuhan kebutuhan rasa aman dan nyaman pada bayi. Bagi Responden, diharapkan responden yang mendapatkan pijat bayi dapat merasakan manfaat dan ketenangan tentang kualitas tidur bayi

Tidak lupa ucapan terima kasih kami sampaikan kepada Ristekdikti yang telah membiayai penelitian ini, STIKes Payung Negeri Pekanabru yang memfasilitasi terlaksananya penelitian, Responden yang bersedia meluangkan waktu untuk peneliti dan
Klinik Cahaya Bunda yang memfasilitasi tempat untuk meneliti.

\section{DAFTAR PUSTAKA}

[1] Roesli, Pedoman Pijat Bayi. Edisi Revisi. Jakarta: Trubus Agriwidya, 2013.

[2] Aco Tan, "Pengaruh Pijat Bayi Terhadap Kualitas Tidur Bayi Usia 1-4 Bulan," Glob. Heal. Sci., vol. 3 No. 1, 2018.

[3] M. Field, T., Diego, M., \& Hernandez, "Preterm Infant Massage Therapy Research: A Review," Infant Behav. Dev., vol. 33, no. 2, 2010.

[4] Sekartini, Buku Pintar Bayi. Jakarta: Pustaka Bunda, 2012.

[5] Santi, Buku Pintar Pijat Bayi Untuk Tumbuh Kembang Optimal Sehat \& Cerdas. Yogyakarta: Pinang Merah Publisher, 2012.

[6] Shadik N, "Pengaruh Pijat Bayi Terhadap Kualitas Tidur Bayi Usia 6-12 Bulan di Rumah Bersalin Rachmi Yogyakarta. 2011," Progr. Stud. DIV Bidan Pendidik Sekol. Tinggi Ilmu Kesehat. Aisyiyah yogyakarta, 2012.

[7] P. . Perry, A.G\&Potter, Buku Ajar Fundamental Keperawatan, 4th ed. Jakarta: EGC, 2012.

[8] T. Roma, Seni Memijat Bayi yang Menyejukkan. Jakarta: Ladangpustaka \& Intimedia, 2002.

[9] S. Abdurrahman, "Pengaruh Pijat Bayi Terhadap Kualitas Tidur Bayi di Desa Tabumela Kecamatan Tilango Kabupaten Gorontalo," Fak. Ilmu-Ilmu Kesehat. dan Keolahragaan Univ. Negeri Gorontalo, 2015.

[10] BennetCandJBarlow, "Massage For Promoting Mental And Physical Health In Typically Developing Infants Under The Age Of Six Months. Article Review.," Cochrane Collab. Publ. by JohnWiley Sons, Ltd, 2013.

[11] Dewi, Utami H. G, Fidyah Aminin, "Pengaruh Pemijatan terhadap Kualitas Tidur Bayi Usia 3-4 Bulan di Posyandu 
Gelatik Dan Nuri Kelurahan Tanjungunggat Wilayah Kerja Puskesmas Sei Jang Kota Tanjungpinang Tahun 2014," Ners dan Kebidanan, vol. 1 No. 3, pp. 144-150, 2014. 